\title{
Grupos de adolescentes no espaço escolar: o papel do professor face às fratrias adolescentes
}

\author{
Viviane Neves Legnani \\ Sergio D'Aragão \\ Juliana Morais Spinola \\ Luiza Mader Paladino \\ Universidade de Brasília
}

\section{Resumo}

Esse estudo se concentrou no adolescente e nas suas relações grupais. Desenvolveu-se a pesquisa em uma escola pública que atende adolescentes em situação de vulnerabilidade social. Entrevistamos o staff escolar (diretora, psicóloga e orientadora educacional) e uma entrevista semi-estruturada foi aplicada em professores. Também foram realizadas oficinas com os alunos. Os resultados mostraram que os professores conseguem oferecer uma possibilidade de inclusão social para esses alunos. Os adolescentes demonstraram um bom entendimento sobre as implicações da formação grupal em suas condutas. Por fim, apontou-se a importância da escola fazer uma reflexão junto aos grupos sobre os ideais excludentes construídos pela sociedade de consumo.

Palavras-chave: Educação. Adolescência. Fratrias. Inclusão. 


\section{Groups of adolescents in schools: the role of teachers}

Our object of research focused on adolescents and their group relations. The research was developed in a public elementary school that serves adolescents in situations of social vulnerability. Initially, an interview was administered to the professionals in the school staff (the director, the psychologist and the counselor). Next, semi-structured interviews were administered to teachers and workshops were held with students. The results show that the school professionals have been able to provide an opportunity for social inclusion to these students. The adolescents demonstrated a good understanding of the implications of group forming on their behavior. Lastly, we pointed to the importance of the school in holding a reflection with groups about the contradictions and ideals constructed by the consumer society and their implications on the experiences of adolescents.

Keywords: Education. Adolescence. Fraternities. Inclusion.

\section{Grupos de adolescentes en el espacio escolar: el papel del profesor frente a las fratrías adolescentes}

Nuestro objeto de investigación se centró en el adolescente y sus relaciones grupales. La investigación se desarrolló en una escuela pública de enseñanza primaria que atiende a adolescentes bajo la situación de vulnerabilidad social. Inicialmente entrevistamos a profesionales que integran el staff escolar (directora, psicóloga y orientadora educacional). Posteriormente fueron realizadas entrevistas semiestructuradas con profesores $y$ talleres con alumnos. Los resultados mostraron que los profesionales de la escuela consiguen ofrecer una posibilidad de inclusión social para los mismos. Los adolescentes demostraron un buen entendimiento sobre las implicaciones de la formación grupal en sus conductas. Finalmente, se apuntó la importancia de que la escuela haga una reflexión junto a los grupos sobre las contradicciones e ideales construidos por la sociedad de consumo y sus implicaciones en las experiencias de los adolescentes.

Palabras clave: Educación. Adolescencia. Fratrías. Inclusión. 


\section{Introdução}

Seguramente os seres humanos se identificam com um grupo. Quando não o fazem estão encurvados, estão no fim (J. Lacan).

As fratrias estão presentes desde os primórdios da humanidade. São formações grupais em que os sujeitos se reúnem e sentem-se irmanados por fatores que os ligam - como objetivos, crenças, gostos, etc. -, elementos estes que fazem parte de um modelo ou de um ideal com o qual todos os integrantes se identificam. Na civilização grega a apresentação dos adolescentes às fratrias era feita pelo pai, o qual jurava, nesse momento, que o filho era ateniense e filho de um cidadão ateniense. Tal apresentação dava lugar a um sacrifício, momento em que o jovem púbere oferecia sua cabeleira aos deuses e, após ser admitido na fratria, conquistava o direito de participar do banquete, que sinalizava a integração à comunidade adulta. As fratrias, nesse contexto, representavam um grupo de cidadãos com os quais cada jovem teria laços privilegiados ao longo de toda vida, um espaço social entre o público e o privado, dentro do qual se esperava que se desenvolvesse o indivíduo grego livre (Zaidman, 2010, p. 41).

Desse modo, o contraste é claro: da sociedade antiga para a pós-moderna, o relacionamento dos adolescentes entre si e com os mais velhos se alterou radicalmente. Observa-se que tais grupos extrafamiliares estavam inseridos em uma ordem simbólica maior, aparados pelas figuras dos pais, das leis e dos deuses, enfim, do Outro', para empregar um termo da psicanálise lacaniana, de forma bastante diversa das fratrias adolescentes atuais que se unem em função da situação de desamparo em que vivem. Desamparo que se coloca mediante o esmaecimento do simbólico decorrente da ausência de referencias verticais estáveis, uma vez que o contexto em que vivemos pauta-se em uma visão de mundo na qual as definições clássicas de família, sociedade, lei, gênero, entre outros aspectos, sofreram mudanças significativas e ainda se mostram profundamente cambiantes (Bustamante, 2009).

Para Coutinho (2005), a adolescência elucida esse sintoma contemporâneo e, por estar no centro dos impasses relativos ao laço social, ao mesmo tempo revela e é afetada por ele. Sintoma social que por sua vez engendra configurações subjetivas diferenciadas, pois o que comparece hoje nas depressões atípicas, nos distúrbios da imagem corporal, nas adicções, e, principalmente nos atos antissociais, pouco teria

1. Na teoria lacaniana o outro é empírico e comparece nos intercâmbios sociais do sujeito. 0 Outro representa a lei e as formaç̧ões discursivas que perpassam e compõem a cultura. Assim, o outro materno e o outro paterno são representantes do Outro diante da criança. 
em comum com as matrizes psicopatológicas clássicas do século XX. Essas mudanças ocorrem em virtude dos sujeitos elaborarem imagens de si, dos outros e do sofrimento, tendo por base uma economia inconsciente que se apoia, por sua vez, no material cultural disponível para se manifestar fenomenologicamente (Costa, 2000).

Rassial (2000) assinala que as referidas sintomatologias alojar-se-iam em um estado-limite. Estado marcado por alguns impasses cruciais que se deram durante 0 processo de constituição subjetiva, os quais apontariam na adolescência para uma suspensão da operação adolescente em que se deveria validar a metáfora paterna², inscrita na infância, no percurso do Édipo. Para o autor, há também uma proximidade do estado-limite com a posição do que seria um sujeito pós-moderno, “o qual se mostra em pane em seu pensamento, em seus investimentos e nas diferenciações entre o discurso e o agir" (Rassial, 1997, p. 38). Ou seja, um sujeito que se mostra como um adolescente em crise, justamente por não ter the sido possível efetuar o que o autor denomina de operação adolescente, não conseguindo, assim, validar a produção de novos nomes-do-pai para além do âmbito familiar, pois os nomes-do-pai - agora no plural , terão de operar em diversas convocações de substituições como, por exemplo, a que se dá no campo da sexuação ou a que subsidia a escolha de uma profissão.

0 efeito deste aprisionamento subjetivo faz com que o sujeito, mesmo na idade adulta, tenha sérias dificuldades em realizar investimentos nos campos afetivo e do trabalho, permanecendo, dessa forma, vinculado a sua família em uma posição de dependência em relação às figuras parentais, ainda que parcial. Em suma, em um mundo volátil, cabe ao adolescente ampliar seus laços sociais em uma posição subjetiva na qual não se pode estar colado ao discurso familiar. Além dessa incerteza que o constitui, encontrará outras faltas de garantias no campo social. Esse é o preço subjetivo extra que os adolescentes contemporâneos pagam. É importante frisar que não existem diferenças significativas entre as posições subjetivas dos adolescentes empobrecidos com a daqueles das classes sociais mais favorecidas, ou seja, ser adolescente na contemporaneidade faz parte de um campo circunscrito de experiências muito particulares e semelhantes (Lesourd, 2004).

2. A metáfora paterna introduz o significante Nome do Pai. É a lei sobre a união narcísica entre mãe e filho, lei enunciada em Nome do Pai, a qual possibilita ao sujeito que faça laços sociais perpassados pelo desejo, ao mesmo tempo, por renúncias pulsionais. 


\section{A escola e os grupos de adolescentes}

De forma paradoxal às dificuldades subjetivas acima discutidas, observa-se uma glamourização em torno da adolescência construída no capitalismo avançado, que passou a ser atrelada aos ideais de consumo, à beleza mercadológica e à exaltação da liberdade individual, valores estes hegemônicos e ditados pela indústria cultural. Ao mesmo tempo, a angústia se faz presente nas relações sociais pela via do excesso. Excesso de informação, de objetos massificados a serem consumidos, olhados e ingeridos. Vive-se hoje sob o imperativo do gozo (Birman, 2006). Essa oferta ampliada de objetos atinge a todos e dificulta a canalização da energia psíquica do adolescente para a construção de um projeto para o futuro.

Nesse contexto, os adolescentes dos estratos econômicos mais abastados gozam de uma longa situação de moratória, durante a qual aguardam a integração ao mercado de trabalho, ficando, portanto, sem uma definição de um espaço ou de um papel específico (Birraux, 1996). Para os adolescentes das camadas empobrecidas das grandes cidades brasileiras, essa inserção se dá de forma mais rápida; mesmo assim, tentam continuar o processo de escolarização visando melhores oportunidades no mundo do trabalho. Essa concepção de moratória é fiel à etimologia da palavra adolescência, a qual tem sua origem no latim ad (para) + olescere (crescer); portanto adolescência significa, strictu sensu, crescer para. Pensar na etimologia da palavra nos remete à ideia de desenvolvimento, de preparação para o que está por vir, algo já estabelecido mais à frente; preparação para que a pessoa se enquadre neste à frente que está colocado (Pereira; Pinto, 2003). Assim, o que está à frente hoje para os adolescentes, independente da classe social na qual estejam inseridos, é que se enquadrem na sociedade de consumo. É o potencial de consumo que irá determinar o grau de inclusão ou de exclusão social para cada um (Betts, 2004).

De uma forma geral, os fins da educação familiar ou escolar, conforme se configuraram no capitalismo, não são outros senão os de incluir o jovem em um exigente mercado de trabalho, sendo que neste processo de inserção, muitas vezes, há uma valorização, por parte da comunidade escolar ${ }^{3}$, dos traços de individualismo e de competitividade que se mostram nos adolescentes, bem como uma relativização da solidariedade social. Considerando tal fragmentação simbólica e, ao mesmo tempo, a densa idealização que se instaurou em nosso tempo, constata-se que é justamente nas fratrias que o

3. Uma reportagem publicada em outubro de 2011, no jornal de maior circulação de Brasília destaca que as escolas, voltadas para a classe média alta brasiliense, prometem bens (tablets e carros) para os alunos do ensino médio que tiverem as melhores classificações no vestibular da Universidade de Brasília. 
adolescente buscará um refúgio para ampliar suas significações sobre o mundo. É a possibilidade de uma nova inscrição social, de um espaço de expressão para que o sujeito consiga elaborar as perdas relativas às identificações do tempo da infância estabelecidas com as figuras parentais e, ao mesmo tempo, projetar-se para o futuro. Diante desse quadro surge a pergunta: como o professor ou professora de uma escola que recebe alunos das camadas empobrecidas e que se envolveram ou estiveram envolvidos em situações de violência, pode se colocar como um mediador ou mediadora entre as exigências contraditórias e megalomaníacas do contexto contemporâneo e os laços sociais que fazem em grupos os seus alunos adolescentes? Legnani, Mendes e Batista (2004) com base em uma pesquisa realizada em uma escola pública na periferia de Brasília, destacam que o cotidiano escolar é um lócus privilegiado para que se constituam diferentes modos de relações grupais. No campo de possibilidades, existem grupos que oscilam para o pólo da ilusão de autossuficiência, fundada no narcisismo. Outros grupos tendem a se pautar pela dimensão da alteridade e heterogeneidade.

As gangues que se formam nesses espaços podem ser pensadas, a partir do texto freudiano, como um tipo de grupo no qual se diluem as diferenças individuais e o papel do líder é o de demonstrar que todos juntos formam um grupo forte, ameaçador e com poder. Já nas fratrias, o laço social preponderante leva os sujeitos a ampliarem suas margens de significação pela constatação da semelhança na diferença, que se dá com a entrada do outro no eixo horizontal. Nesses grupos, não há fixidez para o lugar da liderança (Kehl, 2000; Costa, 2000). Lacan (1953/54 -1979) assinala que o sujeito, preso a uma relação especular, diante da não realização de seu desejo e sem a devida simbolização para essa falta, comparece em um lugar de concorrência, de rivalidade absoluta com o semelhante. Na impulsividade que comparece nas atuações ${ }^{4}$ dos adolescentes que se agrupam em gangues, encontram-se os elementos de uma aspiração indefinida de destruição do outro, justamente pela ausência de um desejo reconhecido e mediado pelo Outro. Também nessas passagens ao ato percebe-se uma postura de heteronomia, de impossibilidade de se alicerçar pensamentos e ações a partir de um ponto de vista próprio em função de não disporem de uma formação conceitual e cultural para analisar e pensar as complexas relações que compõem o cenário social: “A violência é muda, é o ato desprovido de simbolização, é a crueza da realidade perante a qual se pode reagir, é como se a dor se instalasse diretamente no corpo por não haver filtros mentais que atuem como suporte" (Bustamonte, 2009, p. 67).

4. Segundo Lacan (2005) a passagem ao ato difere-se do acting out por ser impulsivo e ser uma espécie de saída de cena ou mesmo de desistência do Outro. 
Tendo como foco essas questões, Legnani, Mendes e Batista (2004) apontam que a escola - que deveria exercer um papel relevante na diluição desse tipo de laço social nos grupos - tem demonstrado uma notória dificuldade para aumentar a gama dos recursos simbólicos e críticos dos adolescentes por estar inserida em um mundo rápido, instável e imagético. Há um mal-estar generalizado que a faz recuar, paralisar e ter dificuldades para cumprir sua função, deixando, muitas vezes, os discentes desprovidos de referências e entregues, portanto, aos seus próprios recursos sociais, cognitivos e subjetivos. Principalmente junto aos alunos das camadas empobrecidas, o sistema escolar cria uma recusa do ato educativo, alegando ser vítima de uma clientela inadequada. Por conseguinte, estes adolescentes ficam destituídos das marcas simbólicas que o conhecimento imprime. Marcas que poderiam auxiliar, inclusive, que cada um pudesse ratificar, nas suas relações sociais, seu eu pensante e não seu eu pensado pelo outro.

\section{Sobre a pesquisa com adolescentes de uma escola no Distrito Federal}

A partir das reflexões geradas pela pesquisa de Legnani, Mendes e Batista (2004), que demonstrou diferentes mecanismos utilizados pelas escolas para excluir gradativamente os alunos que se identificam e integram grupos demarcados como turbulentos e indisciplinados, delineou-se o objeto de investigação que apresentamos neste artigo. Muitas vezes, é nos espaços marginalizados que o adolescente encontra possibilidades de elaboração de novas identificações junto a líderes que neles se apresentam, assim como suporte para se expressar de forma peculiar por meio da estética e da ética. 0 professor ou professora estaria atento e ciente ao que acontece na dimensão grupal?

Partindo desta indagação, realizou-se durante o primeiro semestre letivo de 2011 uma pesquisa qualitativa em uma escola pública de ensino fundamental do Distrito Federal, localizada na região denominada em Brasília como Plano Piloto. Partindo de uma perspectiva inclusiva ${ }^{5}$, a escola recebe alunos adolescentes com vários tipos de vulnerabilidade social, além daqueles com defasagem entre idade e série. São vários os motivos para busca por essa escola específica, que funciona há 30 anos: os discentes são oriundos de regiões administrativas de baixo poder aquisitivo (denominadas popularmente de cidades satélites) ou de municípios do entorno do Distrito Federal que cumprem ou já cumpriram medidas socioeducativas; que foram afastados de suas famílias por medidas protetivas judiciais e estão acolhidos em abrigos; que possuem um vínculo

5. Inclusiva em um sentido mais amplo, de acordo com as premissas da Declaração de Salamanca de 1994. 
familiar frágil, decorrente da violência intrafamiliar ou de uma situação econômica muito precária. Trata-se de uma escola de educação integral, na qual o corpo docente compartilha ativamente de todas as atividades oferecidas aos alunos por entenderem que a escola é um espaço educativo no sentido mais extenso possível. Desse modo, até nos momentos das refeições os professores estão presentes, como estão nas quadras durante os momentos de recreação. Uma das metas pedagógicas da escola é fazer com que os discentes superem as dificuldades relacionadas aos conteúdos das disciplinas de forma que possam seguir em cursos profissionalizantes, que exigem um nível de escolarização cada vez maior. Nessa proposta pedagógica, não existe a lógica da aprovação automática, pois, mesmo sendo diferenciada, a avaliação é realizada e a aprovação para a série subsequente apenas ocorre quando os alunos se apropriam dos conteúdos previstos.

Inicialmente observou-se o cotidiano da escola e entrevistaram-se três profissionais que compõem o staff escolar (diretora, psicóloga e orientadora educacional). Num segundo momento, foram realizados encontros com sete docentes, momento em que se detectou que esses profissionais têm larga experiência profissional e bom nível de qualificação acadêmica. Mediante a aplicação de um roteiro com questões abertas que eram respondidas pelos docentes e anotadas pelos pesquisadores, questionou-se sobre a adolescência, o grupo de amigos durante essa fase, como se instauram as lideranças e o papel dos professores e professoras diante dos adolescentes. Em um terceiro momento, foram realizadas oficinas de construção de fanzines com quatorze alunos na faixa etária de doze a dezoito anos. A construção de fanzines se constituiu como fio condutor para uma melhor compreensão da cosmovisão desses adolescentes. Em outras palavras: esse instrumento operou como um dispositivo para a obtenção de formações discursivas do grupo sobre temas como adolescência e escola, relação entre alunos e professores, formação de grupos e a figura do líder para a coesão grupal. Optou-se pelo fanzine por apresentar uma linguagem próxima ao universo dos adolescentes e por sua faceta dinâmica e visual. Equivalente a uma história em quadrinhos, o fanzine agrega possibilidades artísticas mais amplas como colagem, poesia, música, desenho, etc. Ademais, tem a capacidade de ser reproduzido com facilidade, aumentando o grau de divulgação do conteúdo do material. Outro ponto importante para a escolha desta linguagem é que ela agrega uma expressão livre onde quem produz é independente para criá-la da forma como achar melhor. Em suma, os adolescentes produziriam um projeto coletivo e em torno dele coletamos formações discursivas sobre as temáticas estudadas.

Por meio desses recursos metodológicos e, de forma pertinente com o campo conceitual adotado, o da teoria psicanalítica, utilizou-se na análise desse material, o 
método clínico, o qual se instrumentaliza por meio da escuta das produções objetivas e subjetivas dos sujeitos, que se manifestam através da linguagem. Desse modo, estabeleceu-se uma análise dos dados obtidos, mediante a proposição de que as falas dos sujeitos emergem como produções de suas histórias de vida que mesclam uma realidade social e objetiva e, ao mesmo tempo, uma realidade psíquica e subjetiva.

\section{As entrevistas com os docentes}

As concepções dos professores ${ }^{6}$ sobre a fase da adolescência são consoantes às apresentadas por Birraux (1996), durante a qual existiria um “impacto da modificação pubertária sobre o espaço das representações psíquicas, o qual produz uma tensão entre a identidade e a identificação, na integração do corpo sexuado e em termos de separação-individuação" (Birraux, 1996, p. 6). Isso fica claro nos recortes seguintes:

Momentos de dúvidas e incertezas (Júlio, professor de artes).

É quando contestamos, aprendemos a dizer não para provocar (Cássio, professor de histórial.

[...] pede-se limite mesmo sem querer (Tales, professor de informática).

0 paradigma de estado de moratória fomentado pelo capitalismo tardio também se mostra: Fase de vácuo, o adolescente até se definir fica no vazio (Rosa, professora do ciclo básico de alfabetização).

Com respeito às fratrias, é bastante precisa a percepção dos docentes tanto da importância destas como suporte e refúgio simbólico, quanto dos perigos que uma identificação, que poderia ser classificada, segundo a terminologia lacaniana, como imaginária:

Os amigos vão forjar a personalidade [...] pode-se entrar em um buraco sem fundo (Lia, professora de ciências).

[...] podem dar suporte, mas podem levar o adolescente para o caminho pior (Júlio, professor de artes).

Se o adolescente entra em um grupo negativo, sem a família e a escola para apoiar tudo se complica (Carla, professora do ciclo básico de alfabetização).

Em relação à questão da liderança nos grupos, depreende-se dos relatos de alguns professores, uma ideia da liderança como uma característica inata de alguns sujeitos, e, portanto, os líderes surgiriam espontaneamente:

6. Os professores foram identificados com nomes fictícios para preservar a identidade das entrevistadas. 
É o carisma que faz um líder. Nasce com a pessoa (Cássio, professor de história).

É o mais descolado, o mais valente (Lúcia, professora de português).

Nesse último recorte transparece a suposta ligação da liderança com outras habilidades, sobretudo, a capacidade de expressão e comunicação, isto se faz presente também nas representações de outros docentes: 0 líder é o mais popular e sabe mandar (Lúcia, professora de português).

[...] é persuasivo e se comunica com maior facilidade (Rosa, professora do ciclo básico de alfabetizaçãol.

[...] é quem tem voz ativa, representa a vontade do grupo e se impõe ao mesmo tempo (Tales, professor de informática).

E a percepção do risco de uma identificação imaginária que comparece: Aqui na escola muitos obedecem sem questionar (Júlio, professor de artes ).

As identificações correspondem ao mecanismo de construção do sujeito, que se particularizam a partir da soma de uma série de traços tomados para si no contato com o outro, com a linguagem e com a cultura. Portanto, um grupo, ao circunscrever um novo ambiente social, proporciona possibilidades de alterações subjetivas em cada um de seus componentes. Freud (1921/1996) aponta que ao se inserir no grupo o sujeito se liga por laços libidinais ao líder e também aos demais membros do grupo. Há um apaziguamento, pois as diferenças de cada um tendem a se diluir e os sujeitos comportam-se de forma mais uniforme. A visão dos que se deixam liderar é a de que o líder tem características mais marcantes do que se concebe como o ideal, também é aquele que considera a todos de forma igualitária e, ao mesmo tempo, cumpre a função de os proteger. 0 amor e a admiração por ele dar-se-iam, sobretudo, pela quimera de que este seria capaz de formular um discurso que afiançaria ao sujeito um lugar social sem maiores riscos e incertezas.

O caráter imaginário se desvenda no grupo quando a identificação com o líder e com os demais integrantes funcionariam de acordo com uma lógica que, ao se somarem diversos indivíduos, seria tamponado aquilo de que cada um carece, encobrindo, portanto a falta que a castração simbólica provoca. Tal lógica é fundamentalmente ilusória, pois um hiato sempre surge em algum lugar e a completude, mesmo que almejada, jamais se faz presente. 0 mal-estar que se instaura no grupo revela essa impossibilidade, mesmo assim, os vínculos persistem porque o medo da ruptura grupal gera pânico, como afirma Freud em seu trabalho de 1921, pois evidenciaria o inexorável desamparo de cada um e revelaria a ausência de um sentido pleno e certeiro a ser atribuído à vida e à condição humana.

Nos discursos produzidos pelos docentes, percebeu-se um raciocínio estanque para se pensar as formações grupais. Esse entendimento pode ser contraproducente, na medida em que pode aumentar a tensão e o sentimento de inadequação, por exemplo, 
de um adolescente que se identifique com uma liderança não afeita ao modelo esperado pela equipe escolar. Se tal visão, regulada em um viés maniqueísta sobre os grupos, for a base para os conselhos e orientações dadas aos alunos, pode-se inferir que a mesma não leva em consideração que as identificações são múltiplas e internas ao sujeito, que a eleição de um líder e a inserção em um determinado grupo passam por questões inconscientes, que se relacionam com o narcisismo e com o ideal.

Os adolescentes, nas concepções dos docentes, estão em uma posição de fragilidade e de submissão às formações grupais, as quais influenciam a conduta do adolescente. Existe uma preocupação em diluir a constituição de lideranças com características autoritárias e centralizadoras, mas não uma clareza sobre a importância de se colocar em questão a dimensão imaginária do grupo, ou seja, de questionar juntos aos alunos, a posição de passividade individual para se sentir sustentado pela força e segurança que o grupo pode oferecer.

Sobre o papel dos docentes diante dos adolescentes, a concepção de que representam uma referência e um suporte identificatório é recorrente:

Somos referências para os alunos. Principalmente os professores homens, pois eles, normalmente, não têm o pai por perto (Cássio, professor de história).

0 papel é o de fornecer parâmetros e de criar um forte vínculo afetivo com eles para ser escutado (Rosa, professora do ciclo básico de alfabetização).

Aqui na escola o professor deve ser um espelho para os alunos verem que podem ter um futuro melhor através do trabalho (Tales, professor de informática).

Como já se discutiu, o contexto contemporâneo acentua o sentimento de desamparo dos jovens e, ao mesmo tempo, sobrevaloriza traços de um sujeito supostamente completo, apto para o sucesso e conquistas no mercado de trabalho. Nessas circunstâncias, uma dura distância instaura-se entre a posição dos jovens das camadas empobrecidas e esses ideais, os quais, muitas vezes, são percebidos por eles como inatingíveis. 0 adolescente precisa de suportes identificatórios para conseguir se deslocar orientando-se pelo seu desejo, pois diante da falta dessa ancoragem a tendência é pautar suas vivências sociais modulando-as no campo do 'eu ideal'. Na adolescência quando prepondera essa instância fundadora do narcisismo, prevalece uma fixidez, uma lógica do eu sou ou eu não sou, do tudo ou nada, encastelando o desejo do sujeito. No campo do ideal do eu, ao contrário, pressupõe-se uma falta a ser - a qual, quando não devastadora - impulsiona para o futuro, o ideal está adiante e precisa de movimento e ações para ser alcançado.

A conceituação freudiana de 1914, no texto Sobre o narcisismo: uma introdução, destaca que no alicerce do sujeito reside um narcisismo advindo da constituição do eu 
ideal. Porém, durante a dialética edipiana, o pai estipula à criança que ela deve renunciar ao seu gozo narcisista inicial na relação com o Outro materno, para obter outro tipo de satisfação, que é também narcísica, mas que implica um mérito da criança. Mérito agora, por conseguir se adequar às normas e regras do convívio social e, assim, conseguir agradar aos seus pais. A constituição do ideal do eu, implica que a criança deve suportar a constatação de que não é amada em si mesma como a criança que é, o que dilui sua onipotência. Essa operação instaura o sujeito do desejo, o sujeito que falta ser, e, portanto, que passa a tentar ser. Em suma, a instância do eu ideal é cristalizada, enquanto a instância do ideal do eu garante para o sujeito uma posição de busca e tentativas no campo social. A criação de um modelo inscreve, portanto, a castração simbólica, ao instaurar uma lacuna entre o que somos e aquilo que desejamos ser. A problemática da delinquência apenas se coloca de forma definitiva para o adolescente quando ele sente que não há mais possibilidade de se fazer tais tentativas, ou seja, repousa sobre uma absoluta falta de ilusão (Benhaim, 2008).

Percebeu-se, pelas falas dos docentes, que não há omissão dessa escola em seu papel diante dos discentes. Eles sabem das múltiplas adversidades que os mesmos enfrentam, mesmo assim apostam e tentam se colocar como suportes identificatórios diferenciados em relação ao que esses adolescentes encontram em suas famílias e nas comunidades que estão inseridos, na expectativa de que, por meio da permanência na escola, encontrem alternativas para construir novos ideais que possibilitem aos adolescentes continuarem desejando.

\section{As oficinas com os adolescentes}

Os adolescentes que participaram das oficinas enfatizaram o conturbado processo de escolarização que tiveram até ingressarem na escola atual. Foram várias tentativas mal sucedidas que geraram expulsões de outros estabelecimentos de ensino, o que lhes ocasionou uma significativa defasagem idade/série. Lajonquière $(1996,2000)$, ao discutir a questão da indisciplina no cotidiano escolar, pontua que essa questão, assim como a do fracasso escolar, acaba por mostrar o excesso de idealização presente na educação. Segundo o autor, tais problemáticas convergem em maior ou menor grau para o ponto de fuga da imagem do estudante ideal que recorta o horizonte do imaginário escolar, o qual operaria como um representante de outro maior, que seria o imaginário social em que o educando é posto em um lugar de esperança narcísica por aquele que o educa. Deste lugar, cabe ao adolescente mostrar que quando adulto, no futuro, vai satisfazer toda a potência imaginária do educador ou educadora, ou seja, será um 
sujeito sem falhas. Falhas estas que docentes percebem neles próprios e que, por isso mesmo, denegam o fato de que possam existir, posteriormente, naqueles que por eles hoje são educados. Qualquer desvio desse lugar gera todo tipo de exclusão, desde as mais sutis até se chegar ao ato de recusa da matrícula do adolescente na escola.

Dessa forma, ao conseguirem frequentar e permanecer na escola os adolescentes entrevistados percebem que este é um meio de se afastarem da criminalidade e das drogas: "Venha para escola e pro (sic) livro de fuga do crime" constitui uma frase inserida em um dos fanzines. Frequentar o espaço escolar é uma alternativa ao que poderia torná-los prisioneiros, que seria, então, a inserção no mundo das drogas e do tráfico. Apontaram que se sentem escutados pelos professores e que suas opiniões são consideradas no dia-a-dia escolar. Em relação às regras e normas nos espaços de convivência, também emitem opiniões e, na medida do possível, tentam segui-las. Também colocaram que a maior abertura ao diálogo nessa escola, contribui para a permanência na escola. Entretanto, enquanto representavam essa relação por meio das imagens e textos, concediam à figura do docente, um papel secundário, o que evidencia como o grupo é importante na construção das suas subjetividades.

Em relação às dinâmicas grupais, os adolescentes demonstraram um bom entendimento sobre as implicações da formação grupal em suas condutas e teceram comparações entre os grupos negativos e os que são positivos. Novamente a problemática do uso de drogas e sua relação com o tráfico aparece e é vista como propulsora do ingresso em grupos que teriam implicações nefastas em suas vidas. 0 projeto de futuro que constroem passa, portanto, pelos estudos. Projeto que se mostra idealizado e inserido na sociedade de consumo. Em alguns fanzines, a partir de gravuras de revistas, mostraram que sonham, por exemplo, com festas, carros, etc. Ao falarem e se expressarem visualmente sobre o líder, essa questão também aparece: “São pessoas bem sucedidas, bonitas e com estilo" (autor anônimo). Destacaram que na escola não se sentem liderados por nenhum colega, pois nesse espaço todos tem uma posição semeIhante por poderem enunciar suas opiniões. No entanto, nos ambientes que frequentam nas proximidades de suas casas, reconheceram que lideranças bem demarcadas se fazem presentes: "O líder é aquele que funda um grupo, por isso, pode mandar" (Sandro, 16 anos).

Cotejando as expressões dos discentes com as dos docentes, percebe-se que a escola investigada cumpre um significativo papel na vida desses adolescentes. Ela se coloca como uma alternativa, uma possibilidade de escolha tanto para construir um projeto de futuro, quanto para vivenciar relações sociais menos autoritárias, fundamentadas no diálogo. Chamou-nos a atenção o amplo entendimento que esses adolescentes têm sobre a problemática das drogas a partir dos exemplos advindos de suas famílias e de outros integrantes das suas comunidades, sendo que não há uma demonização 
em relação a essas vivências, apenas uma constatação de ser este é um caminho conturbado e que é preferível evitá-lo. Evitar, portanto, significa não se integrar a grupos em que seriam liderados e obrigados a ingressar no mundo das drogas e do crime, uma vez que, nesses espaços sociais, existem os que fundam o grupo, e, a partir de seus desejos, criam regras e cobram obediência dos demais.

Winnicott (1992) em A tendência antissocial, compreende a entrada na delinquência como uma expressão de esperança. 0 impulso por parte do sujeito, para contrabalançar sua privação, é o de buscar uma sustentação (holding) no ambiente, o que demarcaria a diferença com a psicose, na qual o desastre relacionar-se-ia com o mundo interno e não externo. 0 adolescente procura algo mediante atos impulsivos e, mesmo à deriva, ainda tem expectativa de encontrar o que perdeu, sendo que ao se deparar com um ambiente estável, que ampare sua tensão opera-se uma borda, um contorno para a sua subjetividade, ou seja, um limite. A postura dos docentes demonstra que eles estão cientes desse limite, que é aceito pelos adolescentes por não se colocar apenas em torno das proibições, do significante não, mas, principalmente, por indicar alguns caminhos possíveis que podem ser percorridos.

\section{Considerações finais}

A visão predominante da adolescência, criada em grande parte por teorias psicológicas no século XX, é a de que os adolescentes, com seus inúmeros conflitos, são imaturos. Tal concepção naturalizada pauta-se em uma lógica teleológica, que leva educadores, pais e professores à concepção de que essa fase deve ser vivida até que atinjam a maturidade por meio do ingresso na vida adulta. Assim, apartam-se deles e não concebem que essa etapa da vida é construída nas ações compartilhadas em uma determinada cultura, tampouco concebem os adolescentes como parceiros sociais ativos na sociedade em que vivem, como destaca Bock (2007).

Na escola em que realizamos nosso estudo, não se percebeu essa deserção educativa, pelo contrário, observou-se, em função das diversas situações de vulnerabilidade que atingem os adolescentes, uma atenção diferenciada. Um episódio grupal turbulento ocorreu durante a fase de coleta de dados da pesquisa: um ato de agressão física de um aluno novato na escola, em relação a uma professora provocou um grande tumulto. A força cega da união grupal se instaurou e os demais estudantes se uniram para agredir o grupo ao qual o referido adolescente pertencia, obrigando a instituição a convocar o aparato policial para controlar a violência. Esse episódio demonstra o quanto a postura dialógica e de suporte identificatório adotada pelo corpo docente é 
relevante, não pela demonstração de apreço à professora agredida, mas por corroborar a errância subjetiva e social desses adolescentes, que podem ainda facilmente ser cooptados pelo efeito sedutor da força da coesão grupal.

Em 1930, Freud ao tecer uma crítica às metas grandiosas da educação faz a seguinte colocação: " 0 fato de ocultar aos jovens o papel que a sexualidade desempenhará em suas vidas, não é o único defeito imputável à educação de hoje. Pois ela também peca ao não prepará-los para a agressividade da qual estão destinados a serem objetos" (Freud, 1930/1996, p.138).

A escuta que fizemos dos adolescentes e dos professores nos levou a indagar se estaríamos diante de uma "educação para a realidade", tal como Freud (1930/1996) entende como o ato educativo deve ser: uma educação que abre mão de uma excessiva idealização ao apostar no desaparecimento de uma desmesurada distância entre o aluno real e o aluno ideal.

Por sua vez, a trama social contemporânea denega a árdua realidade da condição humana e ostenta que existe um único ideal a ser atingido, o qual se articula aos significantes: beleza, poder, juventude e riqueza. Todavia, o ideal não é unívoco e tampouco nos deparamos com ele realizado no mundo; e, mesmo errático, ele incide sobre o sujeito. É por meio dele que alguma coisa falta, mesmo nunca tendo se apresentado, em sua inteireza, em momento algum da história humana. A falta por ele inscrita não pode ser tamponada e, sendo assim, move, causa. 0 dever de atingir o ideal baliza as ações do sujeito no mundo e o laço social fica perpassado por renúncias pulsionais para se construir o pacto civilizatório.

Portanto, é o excesso de idealização que se mostra nefasto, isto é, o encerramento do ideal em torno de alguns significantes cujas exigências são intangíveis. 0 efeito de tal fechamento é o de engendrar uma legião de ressentidos quando se percebe que as tentativas de atingir o ápice estipulado sempre escapam. No caso da adolescência, os ressentidos, principalmente os mais vulneráveis, podem, por vezes, projetar sua ira contra qualquer outro que esteja em uma posição, por eles suposta, de potência e plenitude, recolocando-se assim a problemática da delinquência.

Com base na pesquisa realizada, concluímos que a escola deve ampliar sua perspectiva pedagógica inclusiva, analisando juntamente com os adolescentes as características excludentes da sociedade contemporânea, de modo a fazer das fratrias, importantes parceiras para interrogar o mundo em que eles vivem e preservando nesses questionamentos a tensão entre adaptação e crítica à realidade (Bueno 2010). Oliveira, Camilo e Assunção (2003) assinalam que os adolescentes precisam sentir que são verdadeiros atores sociais, caso contrário, podem ficar "oscilando entre as posições à margem, como vítimas, ou, eventualmente, como algozes da sociedade" (Oliveira; Camilo; Assunção, 2003, p. 74). 
Em outras palavras: a escola - além de possibilitar deslocamentos na lógica de funcionamento dos grupos fazendo com que os participantes se relacionem com os demais integrantes assumindo sua identidade e enunciando sua própria palavra -, também deve intervir de forma que os adolescentes consigam lançar seus investimentos pulsionais em uma rede simbólica mais ampla.

Defendemos a proposição de que a função da escola não é a de dirigir os estudantes para determinadas escolhas, mas de fornecer - mediante uma problematização e manejo daquilo que para eles se coloca como ideal ou como meta a ser atingida no futuro -, elementos que os levem a refletir sobre suas concepções, buscas e ações no mundo. Nesse sentido, além da postura dialógica, a aposta no processo de transmissão/apropriação do conhecimento não se dá sem consequências. Os docentes, ocupando a posição de mediadores do conhecimento, podem fazer um manejo indireto nos grupos de adolescentes, de modo a aumentar a autonomia dos mesmos. 0 conhecimento, por ser essencialmente marcado pela linguagem e resultante de uma dinâmica construção cultural, representa uma expressão do registro simbólico. Sendo assim, pode vir a operar como aporte crítico para se fazer corte nas relações densamente imaginárias estabelecidas pelo sujeito, não só na escola, mas em todas as suas relações sociais.

\section{Referências Bibliográficas}

BETTS, Jaime. "Tóxicos e manias": sociedade de consumo e toxicomanias. Revista da Associação Psicanalítica de Porto Alegre. N²6, 2004

BENHAIM, Michele. 0 materno e a delinqüência. Ágora (Rio J.) [online]. 2008, vol.11, n.1 [cited 2011-10-31], pp. 9-16. Available from: <http://www.scielo.br/scielo.php?script=sci_arttext \&pid=S1516-1498200800 0100001\&lng=en\&nrm=iso>. ISSN 1516-1498. http://dx.doi.org/10.1590/S1516-14982008000100001.

BIRMAN, Joel. Insuficientes, um esforço a mais para sermos irmãos! Em: kehl, M. R.(Org.) Função fraterna. Rio de Janeiro: Relume Dumará, 2000, pp. 171 - 207.

BIRMAN, Joel. Arquivos do mal-estar e da resistência. Rio de Janeiro: Civilização Brasileira, 2006.

BIRRAUX, Annie. Psicopatologia do adolescente. Dicionário enciclopédico de psicanálise: o legado de Freud e Lacan. Editado por Pierre Kaufmann; tradução, Vera Ribeiro, Maria Luiza X. de A. Borges; consultoria, Marco Antonio Coutinho Jorge. Rio de Janeiro: Jorge Zahar Ed., 1996.

BOCK, Ana Mercês Bahia. A adolescência como construção social: estudo sobre livros destinados a pais e educadores. Psicol. Esc. Educ. (Impr.), Campinas, v. 11, n. 1, jun. 2007. Disponível em <http://www.scielo.br/scielo.php?script=sci_arttext\&pid=S141385572007000100007\&lng=pt\&nrm=iso>. Acessos em 05 ago. 2011. http://dx.doi.org/10.1590/S1413-85572007000100007.

BUENO, Sinésio. Ferraz. Educação, paranoia e semiformação. Educ. rev., Belo Horizonte, v. 26, n. 2 , Aug. 2010 . Available from <http://www.scielo.br/scielo.php?script=sci_arttext\&pid=S0102-

BUSTAMANTE, Ani. Filosofando na escola: como transformar o potencial crítico dos alunos em pensamento filosófico. Tradução de Ricardo Rosenbusch. Petrópolis, RJ: Vozes, 2009. 
COSTA, Jurandir Freire. Playdoier pelos irmãos. Em: Kehl, M. R.(Org.) Função fraterna. Rio de Janeiro: Relume Dumará, 2000, pp. 07 - 32.

COUTINHO, Luciana Gagueiro. A adolescência na contemporaneidade: ideal cultural ou sintoma social. Pulsional - Revista de psicanálise ano XVII, n. 181, 2005.

FREUD, Sigmund. “Sobre o narcisismo: uma introdução" in: Edição standard brasileira das obras completas de Sigmund Freud. Rio de Janeiro: Imago, vol. XIV, 1914/1996.

FREUD, Sigmund. "Psicologia de grupo e a análise do ego" in: Edição standard brasileira das obras completas de Sigmund Freud. Rio de Janeiro: Imago, vol. XVIII, 1921/1996.

FREUD, Sigmund. "Reflexões para o tempo de guerra e morte", Edição standard brasileira das obras completas de Sigmund Freud. v. XIV Rio de Janeiro: Imago, 1915/1996.

FREUD, Sigmund. Além do princípio do prazer". Edição standard brasileira das obras completas de Sigmund Freud. v. XVIII Rio de Janeiro: Imago, 1920/1996.

FREUD, Sigmund. "Mal-estar na civilização" in: Edição standard brasileira das obras completas de Sigmund Freud. Rio de Janeiro: Imago, vol. XXI, 1930/1996.

KEHL, Maria. Rita. A fratria orfã Em: Kehl, M. R.(Org.) Função fraterna. Rio de Janeiro: Relume Dumará, 2000, pp. 209 - 242.

LACAN, Jaques. O seminário livro 1: Os escritos técnicos de Freud. Rio de janeiro: Zahar, 1953-54/1979 LACAN, Jaques. O seminário livro 10: A angústia Rio de janeiro: Zahar, 2005

LAJONQUIÈRE, Leandro de. A criança “sua” (in)disciplina e a psicanálise. Em: Aquino, J. G. (Org.). A indisciplina na escola: alternativas teóricas e práticas. São Paulo: Summus, 1996, pp. 25-37.

LAJONQUIERE, Leandro de. A infância, os adultos e a ilusão de um futuro.. In: COLOQUIO DO LEPSI IP/FE-USP, 4., 2002, São Paulo. Proceedings online... Disponível em: <http://www.proceedings. scielo.br/scielo.php?script=sci_arttext \&pid=MSC0000000032002000400030\&lng=en \&nrm=abn>.

Acesso em 02 outubro de 2011.

LEGNANI, Viviane Neves, MENDES, Maria Gislane, BATISTA, Karla Cristina. A travessia do adolescente e o laço social entre os manos: possibilidades entre a delinquência e a fratria. Em Costa, L.F. \& Almeida T. M. de (Orgs). Violência no cotidiano: do risco à proteção. Brasília: Universa e Liber Livros, 2005, pp. 199-214.

OLIVEIRA, Maria Cláudia Santos Lopes de, CAMILO, Adriana Almeida, ASSUNÇÃO, Cristina Valadares. Tribos urbanas como contexto de desenvolvimento de adolescentes: relação com pares e negociação de diferenças. Revista Temas em Psicologia, 11(1), 2003.

MILLOT, Catherine. Freud Antipedagogo. Rio de Janeiro: Zahar, 2001.

PEREIRA, Elcimar Dias, PINTO, Joana. Plaza. Adolescência: como se faz? - apontamentos sobre discursos, corpos e processos educativos. Fazendo Gênero. Goiânia: Grupo Transas do Corpo, anoVII, n.17, jul./out. 2003.

RASSIAL, Jean-Jaques. O sujeito em estado limite. Rio de Janeiro: Companhia de Freud, 2000.

RASSIAL, Jean-Jacques. A passagem adolescente: da família ao laço social. Porto Alegre: Artes e Ofícios, 1997. 
ROSA, Miriam Debieux; CARIGNATO, Taeco Toma; BERTA, Sandra Letícia. Ética e política: a psicanálise diante da realidade, dos ideais e das violências contemporâneos. Ágora. Rio de Janeiro, v. 9 , n. 1, June 2006. Disponível em <http://www.scielo.br/scielo.php?script=sci_arttext\&pid=S151614982006000100003\&lng=en\&nrm=iso >. Acesso em 31 de outubro de 2011. http://dx.doi.org/10.1590/ S1516-14982006000100003.

WINNICOTT, Donald Woods. Privação e delinquência. São Paulo: Martins Fontes, 1992.

ZAIDMAN, Louise Bruit. Os Gregos e seus deuses: práticas e representações religiosas da cidade na época clássica. São Paulo: Edições Loyola, 2010.

Recebido em outubro de 2011

Aprovado em dezembro de 2011

Viviane Neves Legnani, psicóloga pela Universidade Federal de Minas Gerais, psicanalista, mestre e doutora em Psicologia pela Universidade de Brasília. É professora da Faculdade de Educação da Universidade de Brasília atuando nas seguintes temáticas: clínica psicanalítica; psicanálise e educação; inclusão escolar; grupos na adolescência; psicopatologias da infância e da adolescência. Publicação recente: Psicanálise e inclusão escolar: um redimensionamento do ideário do déficit (Inter-ação, v. 35, p. 151-172, 2010). E-mail: vivilegnanidgmail.com

Sergio D'Aragão, bacharel em Ciências Militares e graduando do curso de Licenciatura em Filosofia na Universidade de Brasília. E-mail: daragaophidgmail.com

Juliana Morais Spinola, graduanda do curso de Licenciatura em Artes Plásticas na Universidade de Brasília. Bolsista de iniciação científica (PROIC/CNPq 2010/2011). E-mail: jumspinoladagmail.com

Luiza Mader Paladino, graduanda do curso de Licenciatura em Artes Plásticas na Universidade de Brasília. Bolsista de iniciação científica (PROIC/CNPq 2010/2011). E-mail: luizamaderpaladinodagmail.com 